turbinals were completely atrophied. After a couple of days in hospital the cords acted normally, and it was then possible to observe in the trachea a large dark mass almost obstructing the lumen. The breathing was still accompanied by stridor. Two masses of green crusts, similar to those in the nose and naso-pharynx and about the size of a pigeon's egg, were coughed up from the trachea. Thereafter breathing was quite free. Under suitable treatment the tracheal condition improved much more rapidly than did the nasal condition.

Arthur J. Hutchison.

Trétrop. - On Resection of the Trachea. "Revue Hebdomad. de Laryngol.," etc., September 5, 1903.

The author performed four resections of the trachea on dogs, excising from one to three rings. The three most important points to attend to in the operation are: (1) To make the two incisions clean and absolutely parallel to each other ; (2) to suture the wound so as to prevent any blood entering the trachea from surrounding tissues; $(3)$ to clear all blood or clot out of both ends of the trachea before suturing. The suture in the middle line behind is tied inside the trachea, all the others are tied outside. They do not include the mucous membrane. They are of very fine catgut. Seven or eight would be enough for an adult human trachea. The other tissues are then sutured in layers and the skin fastened with metal clasps. In one of his operations the author did not make the two incisions parallel to each other; the result was very bad, the stitches all cut out and the wound opened. In all the rest of his operations the incisions were parallel to one another, and at right angles to the axis of the trachea. They all healed without any complications.

Arthur J. Hutchison.

EAR.

Dench, E.-Ossiculectony. “Med. News," February 28, 1903.

The author states that there are three classes of cases suitable for the performance of ossiculectomy: (1) Those cases in which the patient is suffering from what is commonly known as a chronic nonsuppurative otitis media, in which the membrana tympani has always been intact, and for which operative precedures are undertaken, either for the improvement of the function of hearing or for the improvement of certain symptoms-e.g., subjective noises, vertigo, etc. ; (2) those cases in which the operation is undertaken primarily for the relief of chronic suppuration; (3) those cases where, as a result of suppuration, adhesions, etc., exist within the tympanum. In the first class of case no operation should be undertaken unless a most careful examination shows the auditory nerve to be intact, and unless normal or even exaggerated bone conduction exists. Where bone conduction is diminished, and where the upper tone limit is much reduced, operation is absolutely useless. In non-suppurative cases it is often only when the impairment of hearing is noticed in the previously healthy ear that the patient applies for relief. In such cases the author states that not only does the hearing in the ear operated upon improve, but that the progress of the disease in the non-operated ear is slower, and, in fact, appears at times to become arrested. 
Out of 88 cases of chronic non-suppurative otitis operated upon for improvement of the function of hearing, 76 cases were improved, 10 were unimproved, 1 became worse after operation, and in 1 case the result is not known.

Of 92 cases operated upon for the relief of suppuration, 53 were cured, 25 improved, 2 were unimproved, and in 12 the result was unknown. In 9 cases operated upon for the residua of suppuration, and, in which the two larger ossicles were removed for the improvement of hearing, 7 were benefited, 1 case was unimproved, and 1 case remained under treatment.

W. Milligan.

Horne, W. Jobson.-The Clinical Diagnosis and Surgical Treatment of Tuberculosis of the Temporal Bone. "Brit. Med. Journ.," July 11, 1903.

The clinical diagnosis of tuberculosis of the temporal bone may be based upon the following group of symptoms: (1) Absence of pain out of all proportion to the destructive character of the disease ; $(2)$ insidious onset ; (3) marked loss of hearing-power ; (4) extensive destruction of bone, rapid extension to labyrinth, absence of headache and dizziness; (5) progressive and destructive character, leading perhaps to facial paralysis or even severe hæmorrhage ; (6) absence of intracranial complications ; (7) considerable involvement of adjacent glands. These symptoms, although strongly pointing to the existence of a tuberculous lesion, are, however, only relative. The positive proof of the disease depends upon the finding of tubercle bacilli within the tissues of the infected area. This difficulty is materially increased from the fact that tubercle bacilli become broken up in the presence of other organisms and leucocytes. The acid-fast property of tubercle bacilli being due to the presence of a wax in the bacillus, the author is inclined to believe that other bacilli, from a sojourn in the neighbourhood of the ceruminous glands, are capable of absorbing wax and thus becoming acid-fast. He explains the absence of pain in such tuberculous cases as being due to the decomposition of this waxlike product, and the liberation of a product-an alcohol-which produces an anæsthetic effect upon the surrounding tissues. Primary tuberculosis of the ear is met with in young children, probably much more frequently than is usually supposed, and is associated with an early and considerable enlargement of the adjacent lymphatic glands. In secondary infection of the ear by tubercle the glands are comparatively seldom enlarged. In primary cases glandular involvement should be thoroughly dealt with.

W. Milligan.

Leaven, H. N.-Otitis Media. "Amer. Pract. and News," January, 1903.

In a series of 100 post-mortem examinations made by Ponfick among infants under three years of age, and dying of various acute and chronic diseases, and where otitis media was not suspected in the majority of cases, it was found, however, to be present in all but 9 cases-unilateral in 13, bilateral in 73. Barth, of Leipzig, found otitis media to be present in nearly 80 per cent. of 600 infants. Many other similar statistics are in existence, which go to show the extra. ordinary frequency of affections of the middle ear in young children.

The importance of examining the ears in young children is strongly 
insisted upon by the author, who sums up his paper with the following conclusions:

1. Earache in children is generally caused by acute inflammation of the middle ear, suppurative or non-suppurative.

2. Infants and young children may have suppuration of the middle ear without giving satisfactory evidence of pain or without rupture of the drum membrane.

3. Otitis media is nearly always present in acute infectious diseases of the gastro-intestinal and respiratory tracts of young children, and probably stands in a causative relation to gastro-enteritis and bronchopneumonia.

4. The cause of death in many acute and chronic infectious diseases, in meningitis and in the exanthemata, is the result of unrecognised and untreated diseases of the middle ear.

W. Milligan.

Snow, Sargent S.-Conservatism in the Treatment of Acute Mastoiditis. "Journal of the Amer. Med. Assoc.," January 31, 1903.

The object of this paper is the advocacy of securing effective drainage of the tympanic cavity by means of a free tympano- Wild incision, and the keeping of inflammatory action and pus formation within bounds by the regular and methodical application of cold or heat.

The indications for free incision of the membrane are bulging, acute congestion, and severe pain in the ear or mastoid tenderness, even in the absence of congestion of the drumhead. In incising the drumbead the knife should be entered near its lower margin in its posterior segment, and carried round upwards and backwards to the attic. In forty-five consecutive cases so treated this method of free incision entirely succeeded.

W. Milligan.

Trow, Ch.-Mastoiditis due to Gonococcus. "Canadian Practitioner and Review," March, 1903.

The patient, a male, aged twenty-two, was admitted to hospital suffering from mastoiditis. About a month before admission a slight swelling formed behind his right ear, followed by a purulent discharge from the ear and right nostril. The swelling behind the ear extended down over the tissues of the neck. When operated upon, the whole mastoid process was found carious and full of pus. The lateral sinus was surrounded by pus, and a fistula was found through the posterior inferior part of the process leading into the tissues of the neck. Bacteriological examination of the pus before operation showed large numbers of an organism identical with the diplococcus of gonorrhoea. An examination of the pus taken from the mastoid during operation showed organisms having the same appearances and giving the same reactions. The patient denied ever having had gonorrhoea or other venereal affection. W. Milligan.

Zur Muehlen, A. (Riga).-After-Treatment of Radical Operations without Packing. "Arch. of Otol.," vol. xxxii., No. 2.

The writer leaves out the packing after the first or second dressing, a mode of action which he considers to have shortened the duration of treatment. At the operation he removes only as much of the healthy bone as is necessary to expose the diseased bone and all the recesses and cells, so that the cavity may be as small as possible, and conse- 
quently more quickly covered with epidermis. He uses the different forms of "plastic," according to circumstances, always closing the retro-auricular wound primarily. The first tampon of iodoform gauze remains, as usual, for six days; the second, introduced much more loosely, remains for two or three. The flaps are then generally secure, and the packing is left off. The wound is then dressed every day, and the ear irrigated with warm water, a procedure which the writer strongly recommends. If there is much fœetor, a 10 per cent. solution of naphthalin in oil is used. The formation of granulations then appears somewhat exuberant to those who are accustomed to keep down the granulations by means of the tampon, but this is favourable to epidermization. If, however, it is excessive, it can be diminished by means of the sharp spoon after the application of cocaine. In some cases the bony cavity was filled with new tissue to a considerable extent without interfering with the cessation of discharge or the improvement in hearing. Packing has to be used when a tendency to the formation of stenosis is apparent, especially when there is a tendency for membranes to form between the middle ear and the mastoid cavity.

\section{Dundas Grant.}

\section{THERAPEUTICS.}

Renault, A.- Some Cases of Cancer cured by Adamkievicz's Cancroine. "La Presse Méd.," July 18, 1903.

In La Presse Médicale for January 22, 1902, four cases of cancer of the œsophagus cured by subcutaneous injections of cancroine were reported (see Journal of Laryngology, Rhinology, and Otology, June, 1902). Six cases of cancer in various parts of the body are now reported.

CASE 1. Cancer of the Tongue.-A lady, aged fifty-four, with cancer of the tongue of three years' duration, came to Adamkiewicz on January 21, 1902. The tongue, of a bluish-red colour, formed a rounded tumour filling the whole mouth, hard, quite fixed, uneven on the surface, and covered with a thick white coating. Speech was incomprehensible, salivation continuous; nothing but liquids and jellies could be taken. Below the jaw were two long, irregular, hard swellings, that seemed continuous with the tongue and submaxillary glands. The patient was very thin, extremely weak, and could not sleep. Injections were commenced on January 21,1902 . In a few days improvement began: the swelling of the tongue diminished, the submaxillary swellings softened, grew smaller, and so on. On February 12 there remained only a little thickening of the right side, tongue quite mobile, speech clear, food taken easily. February 27 : All pain gone, sleep natural. In the latter half of March patient went to the country. April 28: Tongue appeared practically normal, general health excellent.

[Number of injections was sixteen, but how much was given at a time, and what interval elapsed between the injections, is not stated. No mention is made of any histological examination.]

Case 2. Cancer of Larynx (under the care of Dr. Tutterlin, of Schopfheim, Baden).- [In the report of this case no description is given of the larynx. No histological examination appears to have been made.] Tracheotomy had been performed. There were two large 